\title{
Hypophagic effects of propionate increase with elevated hepatic acetyl coenzyme A concentration for cows in the early postpartum period
}

\author{
S. E. Stocks and M. S. Allen ${ }^{1}$ \\ Department of Animal Science, Michigan State University, East Lansing 48824
}

\begin{abstract}
Thirty multiparous lactating dairy cows were used in a randomized block design experiment to evaluate factors related to the degree of hypophagia from intraruminal infusion of propionate. Cows between 3 and $40 \mathrm{~d}$ postpartum at the start of the experiment were blocked by calving date and randomly assigned to treatment. Treatments were $1.0 \mathrm{~mol} / \mathrm{L}$ propionic acid or $1.0 \mathrm{~mol} / \mathrm{L}$ acetic acid adjusted to $\mathrm{pH} 6$ with sodium hydroxide and infused at $0.5 \mathrm{~mol}$ of volatile fatty acid/h from $6 \mathrm{~h}$ before feeding until $12 \mathrm{~h}$ after feeding. Propionate infusion decreased dry matter intake by $20.0 \%$, total metabolizable energy intake by $22.5 \%$, and plasma $\beta$-hydroxybutyrate concentration by $54.3 \%$ compared with acetate infusion. Effects of treatment on dry matter intake were related to concentration of acetyl coenzyme A (CoA) in the liver; hypophagic effects of propionate compared with acetate increased as liver acetyl CoA concentration increased. Hypophagic effects of propionate are greater for cows with elevated concentrations of acetyl CoA in the liver.
\end{abstract}

Key words: dairy cow, propionic acid, dry matter intake

\section{INTRODUCTION}

Research in rodents suggests that meals can be terminated by a signal carried from the liver to the brain via vagal afferents, which is affected by hepatic oxidation of fuels and generation of ATP (Langhans and Scharrer, 1992; Friedman, 1995). Allen et al. (2005) suggested that, of fuels metabolized by the ruminant liver, propionate is likely a primary satiety signal because (1) its flux to the liver increases greatly during meals (Benson et al., 2002), (2) hepatic extraction of propionate from the portal vein exceeds $70 \%$ (Reynolds et al., 2003), and (3) hypophagic effects of propionate are eliminated by hepatic vagotomy (Anil and Forbes, 1980). Propionate might stimulate satiety by its oxida-

Received September 28, 2011.

Accepted January 19, 2012.

${ }^{1}$ Corresponding author: allenm@msu.edu tion via conversion to acetyl CoA if its uptake by the liver exceeds gluconeogenic flux, or by stimulation of oxidation by anapleurosis of an existing pool of acetyl CoA derived from other fuels (Allen et al., 2009).

Increasing ruminal starch fermentation increases propionate flux to the liver by increasing production of VFA as well as propionate as a fraction of total VFA (Davis, 1967). Increased ruminal starch fermentation reduced feed intake of lactating cows in several experiments reported in the literature, as reviewed by Allen (2000). An experiment from our laboratory demonstrated that a more rapidly fermented starch source almost doubled the fractional rate of starch digestion in the rumen and reduced feed intake $8 \%$ because of a $17 \%$ reduction in meal size compared with a less fermentable starch source (Oba and Allen, 2003a). The reduction in meal size might be because hepatic oxidation was stimulated by propionate (Allen, 2000).

Hypophagic effects of propionate are greater for cows in the immediate postpartum period compared with those in mid lactation (Oba and Allen, 2003b). Beginning prepartum and for several weeks postpartum $(\mathbf{P P})$, cows are in a lipolytic state, when energy requirements for milk production increase at a greater rate than energy consumed. Hyperlipidemia in the periparturient period is initially caused by a reduction in plasma insulin concentration combined with a reduction in insulin sensitivity of adipose tissues (Bell, 1995). Uptake of NEFA by the liver increases greatly (Reynolds et al., 2003), resulting in increased FA oxidation, buildup of acetyl CoA, and hepatic export of ketones. Hepatic oxidation of FA and generation of ATP might suppress feed intake in the periparturient period, and hypophagic effects of propionate may be enhanced because propionate uptake by the liver stimulates oxidation of the existing pool of acetyl CoA (Allen et al., 2009).

The objective of this experiment was to evaluate the relationship between hypophagia from intraruminal infusion of propionate relative to acetate and characteristics of cows in the PP period that are in a lipolytic state. We hypothesized that hypophagic effects of propionate increase when hepatic acetyl CoA concentration is elevated. Propionate is expected to 
stimulate oxidation of acetyl $\mathrm{CoA}$ in the tri-carboxylic acid cycle, causing satiety sooner and decreasing meal size for cows with elevated acetyl CoA concentration in the liver. Understanding the mechanisms controlling energy intake during the peripartum period in cows is vital to maintaining healthy, productive cows.

\section{MATERIALS AND METHODS}

\section{Animals, Housing, and Diets}

The Institutional Animal Care and Use Committee at Michigan State University approved all experimental procedures for this experiment. Thirty lactating Holstein cows were ruminally cannulated at least 45 $\mathrm{d}$ before calving. Cows were housed in individual tie stalls for the duration of the experiment. Cows were fed once daily $(1200 \mathrm{~h})$ at $115 \%$ of expected intake and received a common experimental diet from parturition through the end of the experiment. The experimental diet (Table 1) was composed of corn silage, alfalfa silage, alfalfa hay, ground corn, soybean meal, soy hulls, and a vitamin and mineral mix and formulated to meet requirements for absorbed protein, minerals, and vitamins (NRC, 2001).

\section{Experimental Design and Treatments}

The experiment was a randomized block design with a covariate period. Cows were between 3 and $40 \mathrm{~d}$ PP

Table 1. Ingredients and nutrient composition of experimental diet (\% of dietary DM except for DM)

\begin{tabular}{lr}
\hline Item & Value \\
\hline Diet ingredient & \\
Corn silage & 38.7 \\
Alfalfa silage & 30.2 \\
Alfalfa hay & 6.0 \\
Ground corn & 10.9 \\
Soybean meal & 6.9 \\
Soy hulls & 4.2 \\
Vitamin and mineral mix ${ }^{1}$ & 4.0 \\
Nutrient composition & \\
DM & 51.0 \\
OM & 92.2 \\
Starch & 19.2 \\
NDF & 37.1 \\
ADF & 27.5 \\
CP & 15.9 \\
Ether extract & 3.7 \\
\hline
\end{tabular}

${ }^{1}$ Vitamin and mineral mix contained $24.8 \%$ ground corn grain, $21.5 \%$ dehydrated cane molasses, $11.2 \%$ limestone, $9.6 \%$ blood meal, $9.0 \%$ sodium bicarbonate, $6.6 \%$ dicalcium phosphate, $4.2 \%$ ReaShure choline (Balchem Corp., New Hampton, NY), 3.1\% magnesium sulfate, 2.8\% salt, $2.0 \%$ animal fat, $1.5 \%$ niacin, $1.3 \%$ trace mineral mix, $0.95 \%$ biotin, $0.70 \%$ Yeast Plus (Chr. Hansen, Milwaukee, WI), 0.54\% vitamin ADE premix, $0.32 \%$ selenium yeast, and $0.09 \%$ Rumensin 90 (Elanco Animal Health, Indianapolis, IN). at the start of the experiment and were assigned to block by calving date, and then randomly assigned to treatment within a block. The experiment was conducted with 5 blocks of cows containing from 4 to 8 cows each within the same calendar year. The length of the experiment was $3 \mathrm{~d}$ for each block of cows, including a covariate day to establish baseline values for all measurements on d 1. Day 2 of the experiment was a rest day with no treatment or sampling. Treatments were propionic or acetic acids $(1 \mathrm{~mol} / \mathrm{L}$, adjusted to $\mathrm{pH}$ $6.0 \pm 0.1$ with sodium hydroxide) continuously infused into the rumen at $0.5 \mathrm{~mol}$ of VFA/h from $0600 \mathrm{~h}$ to $2400 \mathrm{~h}$ (9 mol/18-h infusion) on $\mathrm{d} 3$ of the experiment. Solutions were infused at $500 \mathrm{~mL} / \mathrm{h}$ using peristaltic pumps (\#78016-30, Cole-Parmer Instrument, Vernon Hills, IL) with Tygon tubing (1.6 mm i.d.) from individual containers that were manually refilled with 500 $\mathrm{mL}$ of treatments hourly to ensure accurate infusion rates per hour. Infusions began $6 \mathrm{~h}$ before feeding to reach a steady-state VFA concentration in the rumen before starting the monitoring of feeding behavior.

\section{Data and Sample Collection}

Cows were blocked from feed from 1000 to $1200 \mathrm{~h}$ daily to allow for weighing of orts, collection of orts samples, and offering feed. Samples of all diet ingredients $(0.5 \mathrm{~kg})$, the TMR $(0.5 \mathrm{~kg})$, and orts $(12.5 \%$ of the remaining feed) were collected daily and composited into one sample per cow per block for analysis. Body weight and BCS were recorded on $\mathrm{d} 1$ of the experiment. Body condition was scored by 3 trained investigators on a 5-point scale, where $1=$ thin and 5 = fat, as described by Wildman et al. (1982). Cows were milked twice daily at 0400 and $1700 \mathrm{~h}$ in the milking parlor, with the exception of the covariate day and infusion day, when cows were milked in their stalls. Milk samples were collected from each milking during the covariate day and analyzed for fat, true protein, lactose, and SNF by Michigan DHIA (AOAC, 1997).

Blood, rumen, and fecal samples were collected every $6 \mathrm{~h}$ for $24 \mathrm{~h}(\mathrm{n}=4)$ during the covariate day. Rumen fluid samples were collected from 5 different sites in the rumen, squeezed through a nylon screen, and $\mathrm{pH}$ was determined immediately. Samples were then frozen at $-20^{\circ} \mathrm{C}$ for later analysis of VFA and ammonia- $\mathrm{N}$ concentrations. Fecal samples were collected and frozen at $-20^{\circ} \mathrm{C}$ for later analysis to determine diet digestibility for use in calculating ME intake. Blood samples were collected via coccygeal venipuncture into 2 Vacutainer tubes (Becton Dickinson, Franklin Lakes, NJ): 1 with potassium EDTA and 1 with potassium oxalate and sodium fluoride (as a glycolytic inhibitor). Blood samples 
were cooled on ice until centrifuged at $2,000 \times g$ for 20 min (within 12 min of sample collection); plasma was then harvested and frozen at $-20^{\circ} \mathrm{C}$ for later analysis of metabolites and hormones. A 1-mL aliquot of plasma from each potassium EDTA tube was stored with $0.05 \mathrm{M}$ benzamidine (final concentration) to prevent enzymatic degradation of glucagon. Liver tissue was collected by needle biopsy (Bradford and Allen, 2005) once before feeding at the end of the covariate day and stored at $-80^{\circ} \mathrm{C}$ until analysis for acetyl CoA concentration.

Feeding behavior was monitored for $12 \mathrm{~h}$ (1200 to $0000 \mathrm{~h}$ ) on the covariate day and infusion day (d 3). Feeding behavior data (chewing, feed disappearance, and water intake) were recorded via computer every 5 $\mathrm{s}$, which allowed for calculation of meal size, intermeal interval, water intake, and eating, ruminating, and total chewing times (Dado and Allen, 1993). Blood and rumen samples were collected immediately before the start of each infusion period $(0530 \mathrm{~h})$ and immediately after the infusion period ended $(0015 \mathrm{~h})$. The samples were processed and stored as described previously.

\section{Analysis of Samples}

Feed, orts, and fecal samples were dried in a $55^{\circ} \mathrm{C}$ forced-air oven for $72 \mathrm{~h}$ and analyzed for DM concentration. All samples were ground with a Wiley mill (1mm screen, Arthur H. Thomas, Philadelphia, PA) and analyzed for ash, NDF, indigestible NDF, CP, starch, and ether extract. Ash concentration was determined after $5 \mathrm{~h}$ of oxidation at $500^{\circ} \mathrm{C}$. Concentration of NDF was analyzed according to Van Soest et al. (1991; method A for NDF) with the inclusion of amylase and $\mathrm{Na}$ sulfite. Indigestible NDF was estimated as NDF residue after $240 \mathrm{~h}$ in vitro fermentation (Goering and Van Soest, 1970); flasks were re-inoculated at $120 \mathrm{~h}$ to ensure a viable microbial population. Ruminal fluid for in vitro incubations was collected from a nonpregnant dry cow fed dry hay only. Indigestible NDF was used as an internal marker to estimate total-tract nutrient digestibility (Cochran et al., 1986). Crude protein was determined according to Hach et al. (1987). Starch was analyzed using an enzymatic method (Karkalas, 1985) after samples were gelatinized with sodium hydroxide. Glucose was measured by a glucose oxidase method (Sigma Chemical Co., St. Louis, MO). Ether extract was determined using a modified Soxhlet apparatus (AOAC, 1990). All nutrients are expressed as percentages of DM determined by drying at $105^{\circ} \mathrm{C}$ in a forced air oven for more than $8 \mathrm{~h}$.

Plasma samples were analyzed using commercial kits for concentration of NEFA (NEFA HR kit, Wako Chemicals USA, Richmond, VA), BHBA (kit no. 2240,
Stanbio Laboratory, Boerne, TX), insulin (Coat-ACount, Siemens Healthcare Diagnostics, Deerfield, IL), and glucagon (kit no. GL-32K, Millipore, Billerica, MA). Plasma glucose concentration was analyzed using a glucose oxidase method (Sigma Chemical Co.). Plasma and rumen fluid VFA concentrations were determined by HPLC according to Oba and Allen (2003b). Rumen ammonia- $\mathrm{N}$ concentration was determined by colorimetric assay using the method of Broderick and Kang (1980). Liver acetyl CoA was analyzed using the method of King and Reiss (1985) with modifications. Sixty to $80 \mathrm{mg}$ of wet tissue weight of liver was homogenized in $6 \mu \mathrm{L}$ of $100 \mathrm{~m} M$ sodium phosphate buffer (pH $=3.0)$ and $240 \mu \mathrm{L}$ of $3.6 \%$ perchloric acid solution. The homogenized solution was centrifuged at $10,000 \times g$, and the supernatant transferred into an HPLC vial for analysis. Aliquots $(50 \mu \mathrm{L})$ were sampled with a Waters 717 plus Autosampler (Milford, MA), injected onto a Phenomenex Synergi Hydro RP80A column $(150 \times 4.6$ $\mathrm{mm}, 4 \mu \mathrm{m}$; Phenomenex, Torrance, CA) maintained at $30^{\circ} \mathrm{C}$, and absorbance was measured at $254 \mathrm{~nm}$ by using a Waters 486 Tunable Absorbance detector.

\section{Statistical Analysis}

Data from the covariate period were summarized using the Distributions procedure of JMP (version 8.0.2, 2009, SAS Institute Inc., Cary, NC). Linear and quadratic relationships between DMI and covariates of interest were evaluated by regression with JMP. Feeding behavior, intake, and rumen fermentation characteristics data were analyzed using the Fit Model procedure of JMP with the following model:

$$
\begin{aligned}
\mathrm{Y}_{\mathrm{ij}}=\mu & +\mathrm{T}_{\mathrm{i}}+\operatorname{CovDMI}+\operatorname{CovAcCoA} \\
& +\mathrm{T}_{\mathrm{i}} \operatorname{CovAcCoA}+\mathrm{e}_{\mathrm{ij}},
\end{aligned}
$$

where $\mu=$ overall mean, $T_{i}=$ fixed effect of treatment ( $\mathrm{i}=1$ to 2$)$, CovDMI = effect of covariate DMI, CovAcCoA $=$ effect of covariate acetyl CoA concentration in the liver, $\mathrm{T}_{\mathrm{i}} \operatorname{CovAcCoA}=$ interaction between treatment and the covariate acetyl CoA concentration in the liver, and $\mathrm{e}_{\mathrm{ij}}=$ residual (normally distributed). Plasma metabolite and hormone data were analyzed using the same model with CovDMI removed because plasma responses were evaluated as change over the 18-h infusion rather than a mean of the 12 -h period for intake and feeding behavior. Treatment effects were declared significant at $P<0.05$ and tendencies for treatment effects at $P<0.10$. Interactions were declared significant at $P<0.10$. Covariate interactions were removed from the model if $P>0.20$. 


\section{RESULTS}

\section{Variation Among Animals During the Covariate Period}

Results of data collected during the covariate day to provide baseline values for variables of interest are summarized in Table 2. As expected, feed intake and plasma metabolite concentrations were highly variable among cows because of the range in milk yield and day PP. Dry matter intake ranged from 8.0 to $19.5 \mathrm{~kg} / 12 \mathrm{~h}$, ME intake ranged from 50.1 to $143.5 \mathrm{MJ} / 12 \mathrm{~h}$, plasma NEFA concentration ranged from 103 to $1,330 \mu \mathrm{Eq} / \mathrm{L}$, and plasma BHBA ranged from 5.52 to $19.20 \mathrm{mg} / \mathrm{dL}$. Liver acetyl CoA concentration was highly variable, ranging from 5.1 to $106.5 \mathrm{nmol} / \mathrm{g}$ of wet tissue weight and was positively correlated with preinfusion plasma BHBA concentration $(\mathrm{r}=0.62$, quadratic, $P<0.01)$.

\section{Feed Intake, Total ME Intake, and Feeding Behavior}

Propionate infusion decreased DMI 20\% compared with acetate $(12.8$ vs. $16.0 \mathrm{~kg} / 12 \mathrm{~h} ; P<0.001$; Table 3 ) because of a $15.4 \%$ numerical decrease in meal size ( 2.09 vs. $2.47 \mathrm{~kg} / \mathrm{meal} ; P=0.12$; Table 3$)$, with an $8.2 \%$ numerical decrease in meal length (35.8 vs. 39.0 $\mathrm{min} / \mathrm{meal} ; P=0.34$; Table 3$)$. Meal frequency $(P=$ 0.70 ; Table 3$)$ and intermeal interval $(P=0.47$; Table 3 ) did not differ between treatments. Although propionate has greater ME concentration than acetate such that ME of propionate infused was greater than acetate infused (9.22 vs. $5.26 \mathrm{MJ} / 12 \mathrm{~h}$; Table 3), propionate decreased total ME intake (infusion + diet) by $22.5 \%$ compared with acetate (93 vs. $120 \mathrm{MJ} / 12 \mathrm{~h} ; P<0.001$; Table 3 ). Treatment did not affect total daily eating time $(P=0.23$; Table 3$)$; however, propionate tended to decrease total daily ruminating time (170 vs. 204 $\min / \mathrm{d} ; P=0.06$; Table 3 ), and decreased total daily chewing time (350 vs. $399 \mathrm{~min} / \mathrm{d} ; P=0.03$; Table 3 ). Propionate infusion decreased water intake $15.3 \%$ compared with acetate infusion $(61.8$ vs. $73.0 \mathrm{~L} / 12 \mathrm{~h} ; P=$ 0.003; Table 3).

\section{Ruminal pH, Concentration and Profile of VFA, and Ammonia-N Concentration}

Propionate infusion, compared with acetate infusion, did not affect ruminal $\mathrm{pH}(P=0.80$; Table 4$)$, total VFA concentration $(P=0.50$; Table 4$)$, or ammonia-N concentration $(P=0.57$; Table 4$)$. Propionate infusion increased ruminal propionate as a percentage of total VFA $(28.4 \%$ vs. $21.2 \%, P<0.0001$; Table 4$)$, whereas acetate infusion increased ruminal acetate as a percent- age of total VFA $(64.6 \%$ vs. $57.1 \%, P<0.0001$; Table $4)$.

\section{Plasma Metabolites and Hormones Before and After Infusion}

Propionate infusion tended to increase plasma propionate concentration compared with acetate infusion $(P$ $=0.09$; Table 5), and acetate infusion increased plasma acetate concentration compared with propionate infusion $(P<0.0001$; Table 5). Propionate infusion increased plasma glucose concentration $14.8 \%$ (61.1 vs. $53.2 \mathrm{mg} /$ $\mathrm{dL} ; P<0.001$; Table 5) and reduced plasma BHBA concentration $54.3 \%$ compared with acetate infusion (6.09 vs. $13.32 \mathrm{mg} / \mathrm{dL} ; P<0.001$; Table 5). Covariate plasma BHBA concentration was positively correlated to covariate hepatic concentration of acetyl CoA $\left(\mathrm{R}^{2}\right.$ $=0.24$, quadratic, $P=0.006$; Figure 1$)$. Postinfusion plasma insulin $(P=0.54)$, glucagon $(P=0.30)$, and NEFA $(P=0.45)$ concentrations did not differ between treatments (Table 5).

\section{Interactions Between Treatments and Indicators of Metabolic Status}

Interactions between treatment and indicators of metabolic status measured during the covariate day (e.g., plasma BHBA and NEFA concentrations, liver acetyl CoA concentration) were evaluated for DMI response. We observed an interaction $(P=0.05)$ between treatment and liver acetyl CoA for DMI (Figure 2); hypophagia from propionate infusion compared with acetate infusion increased as hepatic acetyl CoA concentration increased. No interactions were detected between treatment and any other metabolite or hormone measured during the covariate day (Table 2).

\section{DISCUSSION}

As expected, ruminal propionate and acetate infusion increased concentrations of propionate and acetate in rumen fluid and plasma, respectively, consistent with a previous experiment from our laboratory at the same infusion rate (Oba and Allen, 2003b). The reduction in DMI by propionate compared with acetate was expected based upon previous experiments (Allen, 2000; Allen et al., 2005). We previously proposed that the hypophagic effects of propionate compared with acetate are related to their effects on hepatic oxidation (Allen, 2000). Propionate can be oxidized by conversion to acetyl CoA (Knapp et al., 1992) and stimulate hepatic oxidation by anapleurosis, whereas hepatic uptake of acetate from the blood is negligible (Reyn- 
Table 2. Characteristics of cows during the covariate period

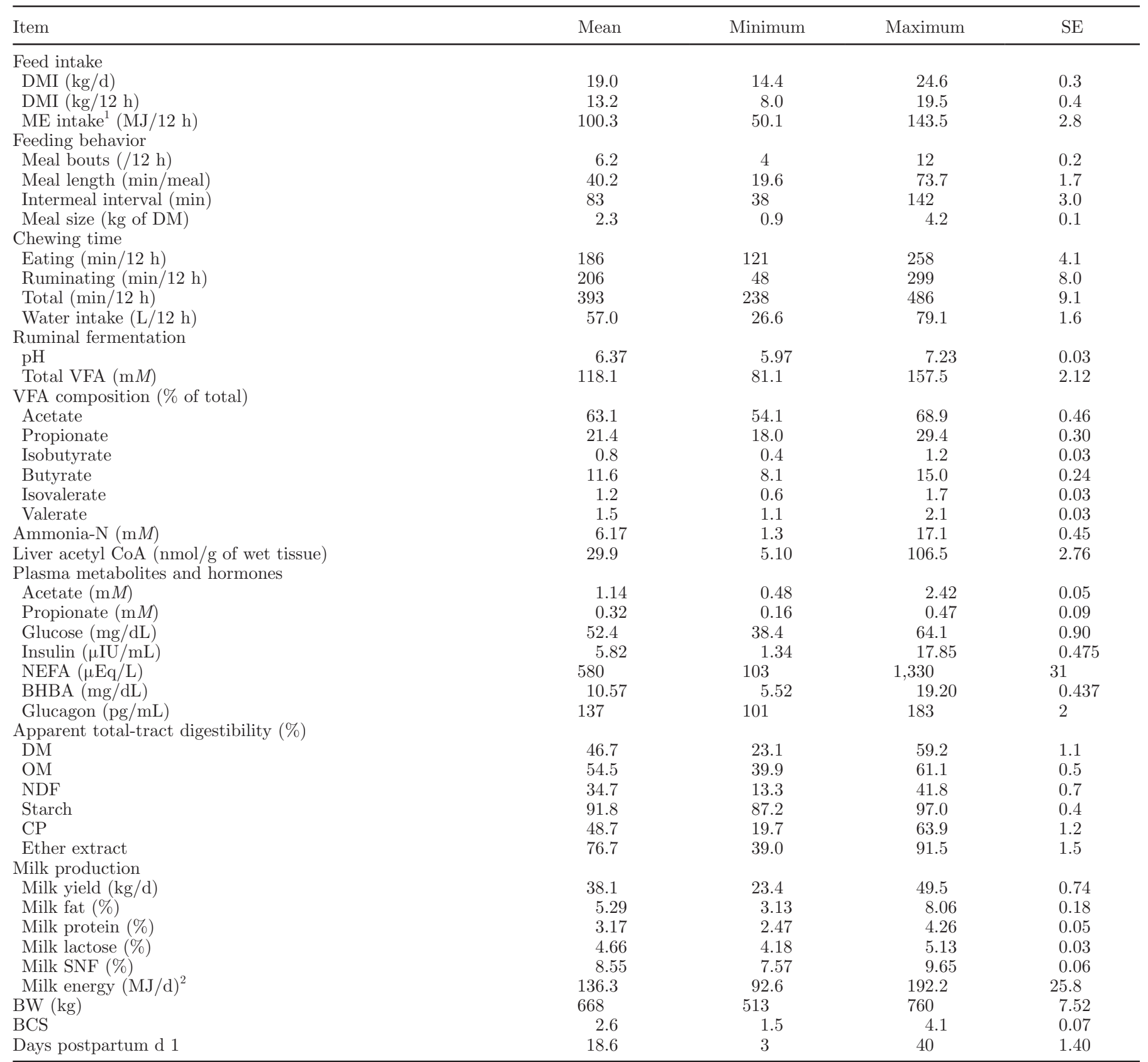

${ }^{1}$ Metabolizable energy intake from diet was calculated according to Oba and Allen (2003b).

${ }^{2}$ Milk energy was calculated according to NRC (2001).

olds, 1995) because activity of acetyl CoA synthetase is low in ruminant liver (Ricks and Cook, 1981). Acetate was used as the control in this experiment to account for mechanisms affecting feed intake that relate to osmotic effects of intraruminal infusions rather than those related to the specific effects of fuels per se (Choi and Allen, 1999). Total ME intake from the diet and infusion was calculated to account for the higher ME of propionate relative to acetate. The $22.5 \%$ reduction in total ME intake in the present study was similar to that of previous experiments at a similar infusion rate of propionate (Oba and Allen, 2003b,c). Previous work in our laboratory showed that propionate linearly decreased ME intake in early lactation dairy cows in a dose-dependent manner as the fraction of propionate in the infusate compared with acetate increased (Oba and Allen, 2003b). Reductions in DM and ME intake in the current experiment were the result of decreased meal 
Table 3. Effects of intraruminal infusion of sodium propionate relative to sodium acetate on feeding behavior and energy intake for cows in early lactation

\begin{tabular}{|c|c|c|c|c|c|c|}
\hline \multirow[b]{2}{*}{ Item } & \multicolumn{2}{|c|}{ Infusion } & \multirow[b]{2}{*}{$\mathrm{SE}$} & \multicolumn{3}{|c|}{$P$-value ${ }^{1}$} \\
\hline & Acetate & Propionate & & Trt & Cov CoA & Trt $\times$ Cov $\mathrm{CoA}$ \\
\hline \multicolumn{7}{|l|}{ Feeding behavior } \\
\hline DMI (kg/12 h) & 16.0 & 12.8 & 0.47 & $<0.001$ & 0.53 & 0.04 \\
\hline Meal size (kg) & 2.47 & 2.09 & 0.170 & 0.12 & 0.33 & 0.82 \\
\hline Meal length (min/meal) & 39.0 & 35.8 & 2.34 & 0.34 & 0.49 & 0.43 \\
\hline Meal frequency (no./12 h) & 6.59 & 6.35 & 0.435 & 0.70 & 0.69 & 0.59 \\
\hline Diet & 115 & 84 & 5.1 & $<0.001$ & 0.17 & 0.32 \\
\hline Infusion $^{3}$ & 5.26 & 9.22 & $\mathrm{NA}^{4}$ & NA & NA & NA \\
\hline Total & 120 & 93 & 5.1 & $<0.001$ & 0.17 & 0.32 \\
\hline \multicolumn{7}{|l|}{ Chewing activity $(\min / 12 \mathrm{~h}$ ) } \\
\hline Eating & 195 & 180 & 8.4 & 0.23 & 0.82 & 0.19 \\
\hline Ruminating & 204 & 170 & 12.6 & 0.06 & 0.54 & 0.97 \\
\hline Total & 399 & 350 & 15.6 & 0.03 & 0.71 & 0.49 \\
\hline
\end{tabular}

${ }^{1} P$-values for treatment $(\mathrm{Trt})$, covariate acetyl $\mathrm{CoA}(\mathrm{Cov} \mathrm{CoA})$, and treatment by covariate acetyl CoA interaction $($ Trt $\times$ Cov $\mathrm{CoA})$

${ }^{2} \mathrm{ME}$ intake from the diet was calculated according to Oba and Allen (2003b).

${ }^{3} \mathrm{ME}$ intake from the infusion was based on energy density of 0.876 and $1.536 \mathrm{MJ} / \mathrm{mol}$ for acetate and propionate (Oba and Allen, 2003b), respectively, and was the same for all cows.

${ }^{4} \mathrm{NA}=$ not analyzed.

size, consistent with previous results (Oba and Allen, 2003b). The slight reduction in water intake was likely a result of the effect of treatment on DMI because DMI and water intake are positively correlated (Woodford et al., 1984), and DMI accounts for the majority of the variation in water intake (Murphy et al., 1983).

Effects of treatment on plasma metabolite and hormone concentrations were as expected and in agreement

Table 4. Effect of intraruminal infusion of sodium propionate relative to sodium acetate on rumen VFA and ammonia-N concentration changes throughout the 18-h infusion period (reported as postinfusion minus preinfusion)

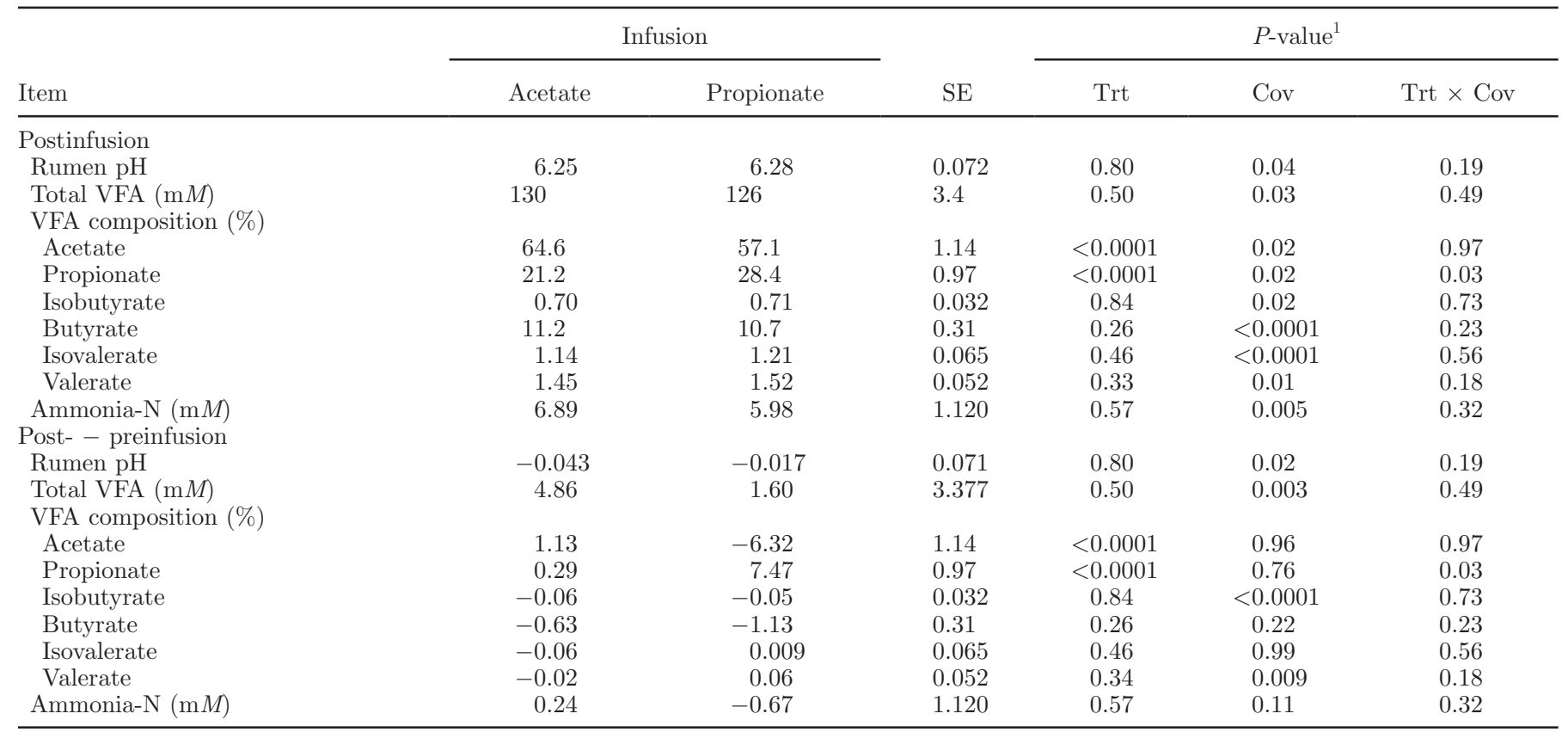

${ }^{1} P$-values for treatment (Trt), covariate (Cov), and treatment by covariate interaction (Trt $\times$ Cov). 


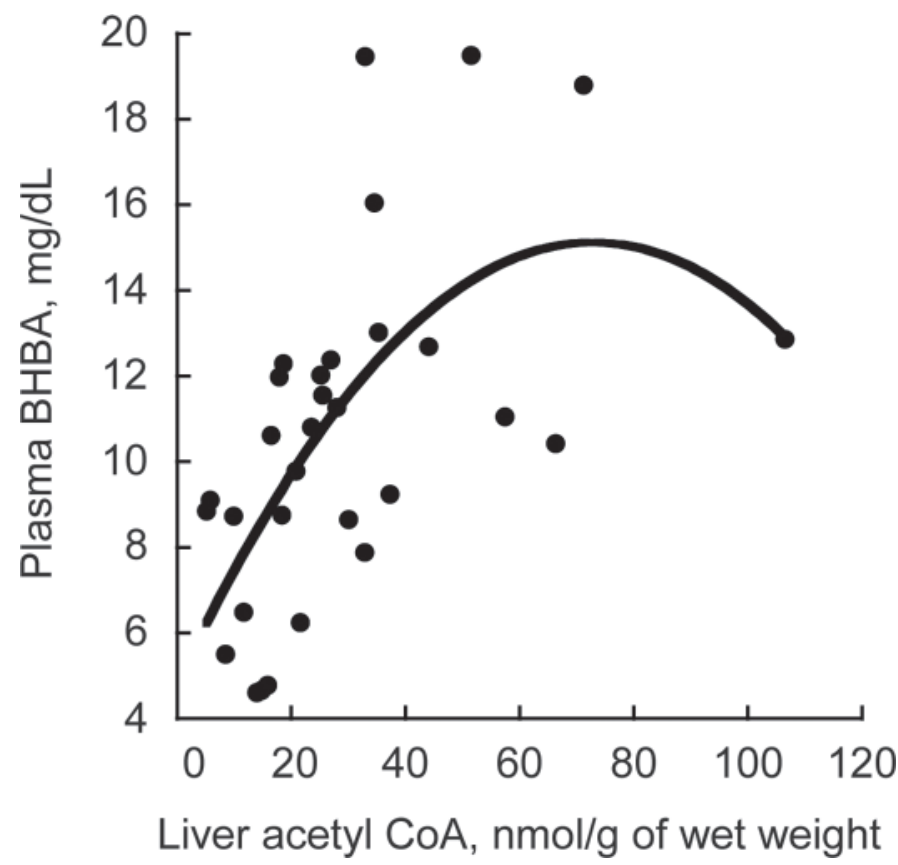

Figure 1. Relationship between liver acetyl CoA concentration during the covariate day and plasma BHBA concentration during the covariate day $\left(\mathrm{R}^{2}=0.24, P=0.006\right.$ quadratic $)$.

with previous experiments (Oba and Allen, 2003b,c). Propionate infusion increased plasma glucose concentration compared with acetate infusion, consistent with previous results (Oba and Allen, 2003b,c), but did not affect plasma insulin concentration. Effects of propionate infusions on plasma insulin concentration have been variable, with no effect of treatment observed in some experiments (Allen et al., 2009).

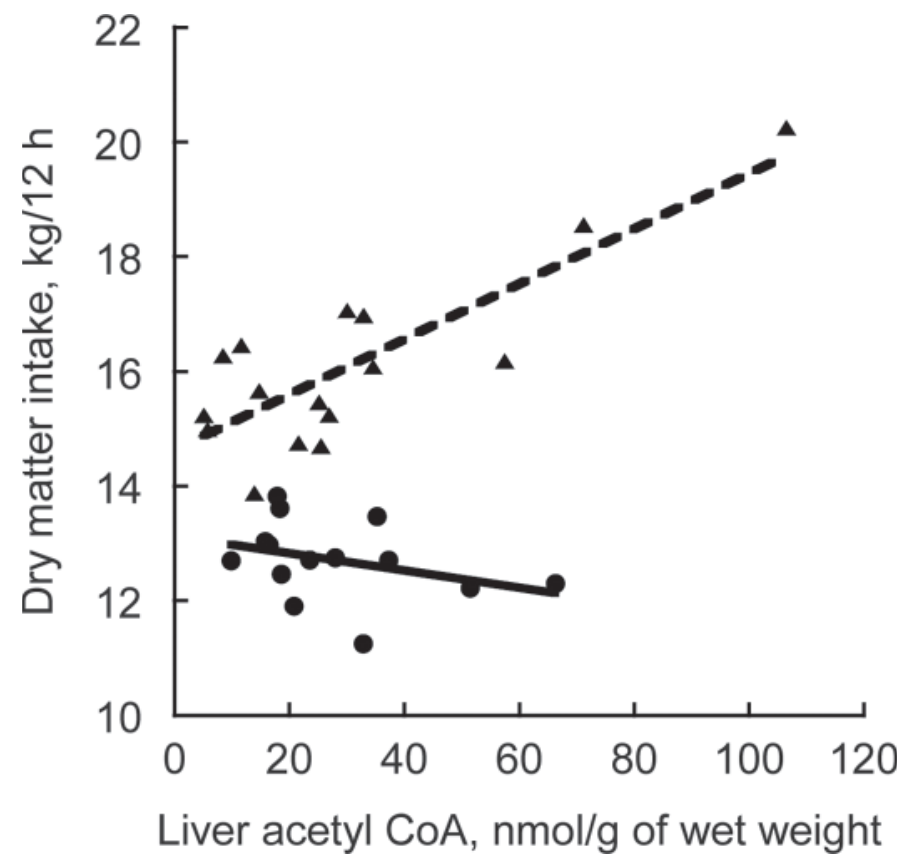

Figure 2. Interaction $(P=0.05)$ between treatment and liver acetyl CoA concentration for DMI during the 12-h infusion period for cows infused with acetic acid (dotted line) or propionic acid (solid line) intraruminally. Equation: DMI $=10.29+1.43 \times \mathrm{A}-0.0026 \times \mathrm{ACoA}$ $+0.033 \times(\mathrm{ACoA}-29.43) \times \mathrm{A}$, where $\mathrm{A}=$ acetic acid treatment and $\mathrm{ACoA}=$ concentration of liver acetyl $\mathrm{CoA}$ in the covariate period .

Propionate infusion decreased plasma BHBA concentration, but did not affect plasma NEFA concentration, consistent with our previous results at the same infusion rate in dairy cows in the early $\mathrm{PP}$ period (Oba and Allen, 2003b). The reduction in plasma BHBA concentration without a reduction in plasma NEFA

Table 5. Effect of intraruminal infusion of sodium propionate relative to sodium acetate on plasma metabolite and hormone concentration changes throughout the 18-h infusion period (reported as postinfusion minus preinfusion)

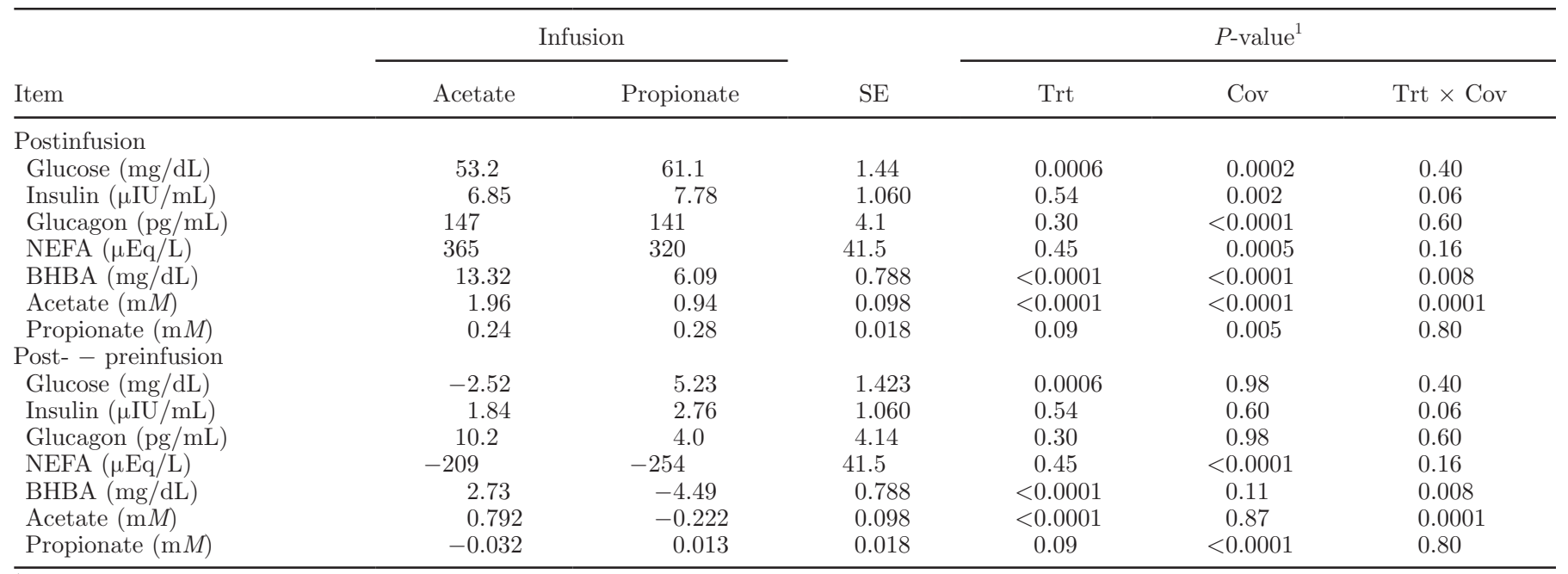

${ }^{1} P$-values for treatment (Trt), covariate (Cov), and treatment by covariate interaction (Trt $\times$ Cov). 
concentration might have been from (1) decreasing $\beta$-oxidation by reducing the transport of long-chain FA (LCFA) into the mitochondria by propionate either by increasing esterification of LCFA in the cytosol (Jesse et al., 1986) or inhibiting carnitine palmitoyltransferase I (CPT1) through conversion of propionate to methylmalonyl CoA (Brindle et al., 1985); (2) reducing ketogenesis from propionate in ruminant liver (Faulkner and Pollock, 1986) by decreasing the activity of 3-hydroxy-3-methyl-glutaryl (HMG)-CoA synthase (Lowe and Tubbs, 1985); or (3) increasing oxidation of acetyl CoA in the tri-carboxylic acid cycle. Although all of the above are possible explanations for the effect of propionate on plasma BHBA concentration, increased oxidation of acetyl CoA is consistent with the hypophagic effect of propionate by stimulation of hepatic oxidation (Allen et al., 2009). Hepatic oxidation of acetyl CoA would increase as propionate supply to the liver stimulates oxidation of acetyl $\mathrm{CoA}$ in the tricarboxylic acid cycle and decreases its export from the liver by inhibiting ketogenesis (Allen et al., 2009). This is expected to increase the rate at which energy charge $([\mathrm{ATP}]+1 / 2[\mathrm{ADP}]) /([\mathrm{ATP}]+[\mathrm{ADP}]+[\mathrm{AMP}])$ increases within meals, decreasing meal size, consistent with our results. Although propionate might also decrease transport of LCFA into the mitochondria, inhibiting $\beta$-oxidation, this is inconsistent with effects of inhibiting or enhancing $\beta$-oxidation on feed intake as reviewed by Allen et al. (2009). Inhibiting transport of LCFA into the mitochondria by blocking CPT1 with methyl palmoxirate (Friedman et al., 1986) stimulated eating in rats, whereas stimulating transport of LCFA into the mitochondria by supplementation of carnitine to transition dairy cows decreased feed intake during the first 2 wk of lactation (Carlson et al., 2007).

The hypophagic effects of propionate, but not acetate, were increasingly pronounced at elevated concentrations of hepatic acetyl CoA (Figure 2). Propionate likely stimulated oxidation of hepatic acetyl CoA, reducing the pool of acetyl CoA available for export as ketones, depressing DM and ME intake. We observed a positive relationship between liver acetyl $\mathrm{CoA}$ and DMI for acetate infusion, possibly because acetyl CoA oxidation in the tri-carboxylic acid cycle was increasingly limited for cows with greater intake, whereas propionate infusion may have enhanced oxidation of acetyl $\mathrm{CoA}$ in the tri-carboxylic acid cycle, as discussed above.

It is unlikely that the effect of propionate infusion on DMI was a result of the observed increase in plasma glucose, because glucose infusions generally do not decrease energy intake in ruminants (Al-Trad et al., 2009; Allen et al., 2009). Larsen and Kristensen (2009) reported that abomasal glucose infusion in postpartum dairy cows $(0.35 \mathrm{~mol} / \mathrm{h}$ from 1 to $29 \mathrm{DIM})$ prevented the increase in DMI and milk yield observed, with control cows receiving no infusion. However, in that experiment, glucose infusion had no effect on plasma glucose concentration, and the glucose infusion tended to increase plasma insulin concentration approximately 3 -fold $(P=0.07)$. In another experiment, Leury et al. (2003) reported that DMI was reduced for early lactation cows that were subjected to a hyperinsulemic euglycemic clamp. The consistently high plasma insulin concentration in both of these experiments likely decreased the rate of gluconeogenesis, resulting in faster oxidation of fuels in the liver within meals, limiting meal size and DMI. Consistent with this, we reported a negative relationship between DMI of mid lactation cows on a highly fermentable diet and mean daily plasma insulin concentration measured before treatment $\left(\mathrm{r}^{2}\right.$ $=0.28, P<0.01, \mathrm{n}=29$; Bradford and Allen, 2007). In the present experiment, propionate treatment increased plasma glucose concentration but did not affect plasma insulin concentration. Therefore, it is more likely that the effect of propionate on DMI was through stimulation of oxidation of acetyl CoA in the liver.

Langhans et al. (2011) contended that enterocytes could act as a fuel gauge to signal satiety and that rat enterocytes are sufficiently innervated to send signals about energy status to the brain. Although propionate is oxidized by enterocytes, acetate is as well (Oba et al., 2004), and flow of acetate from the rumen is greater than flow of propionate because production of acetate in the rumen is greater (Sutton et al., 2003) and it is absorbed more slowly than propionate (Djikstra et al., 1993). Because of this, and because of the interaction observed between treatment and acetyl CoA concentration reported here, it is more likely that the hypophagic effects of propionate are from hepatic oxidation.

\section{CONCLUSIONS}

Feed intake of cows in the postpartum period is likely suppressed by hepatic oxidation of NEFA mobilized from body reserves by homeorhetic mechanisms related to reduced insulin concentration and sensitivity of adipose tissues before parturition. $\beta$-Oxidation of NEFA in the liver increases the pool of acetyl CoA, and propionate uptake by the liver during meals might stimulate its oxidation, causing satiety. Diets containing highly fermentable starch might depress energy intake of cows in the postpartum period over the short term because of rapid propionate production and absorption during meals. Feeding studies evaluating the effect of starch fermentability on energy intake during the postpartum period and adaptive responses to longer term infusions 
of propionate are needed to better understand how to increase energy intake in the PP period.

\section{ACKNOWLEDGMENTS}

This project was supported by National Research Initiative Competitive Grant no. 2008-35206-18854 from the USDA National Institute of Food and Agriculture (M.S.A.) and by USDA National Needs Graduate Fellowship program, grant number 2007-38420-17753 (S.E.S.). We gratefully acknowledge B. J. Bradford (Michigan State University) for contributions related to the initial planning of this experiment, and D. G. Main, R. A. Longuski, and Y. Ying (all of Michigan State University) for technical assistance.

\section{REFERENCES}

Al-Trad, B., K. Reisberg, T. Wittek, G. B. Penner, A. Alkaassem, G. Gäbel, M. Fürll, and J. R. Aschenbach. 2009. Increasing intravenous infusions of glucose improve body condition but not lactation performance in midlactation dairy cows. J. Dairy Sci. 92:5645-5658.

Allen, M. S. 2000. Effects of diet on short-term regulation of feed intake by lactating dairy cattle. J. Dairy Sci. 83:1598-1624.

Allen, M. S., B. J. Bradford, and K. J. Harvatine. 2005. The cow as a model to study food intake regulation. Annu. Rev. Nutr. 25:523-547.

Allen, M. S., B. J. Bradford, and M. Oba. 2009. Board-Invited Review: The hepatic oxidation theory of the control of feed intake and its application to ruminants. J. Anim. Sci. 87:3317-3334.

Anil, M. H., and J. M. Forbes. 1980. Feeding sheep during intraportal infusions of short-chain fatty acids and the effect of liver denervation. J. Physiol. 298:407-414.

AOAC. 1990. Official Methods of Analysis. 15th ed. Association of Official Analytical Chemists, Gaithersburg, MD.

AOAC. 1997. Official Methods of Analysis. 16th ed. Association of Official Analytical Chemists, Gaithersburg, MD.

Bell, A. W. 1995. Regulation of organic nutrient metabolism during transition from late pregnancy to early lactation. J. Anim. Sci. 73:2804-2819.

Benson, J. A., C. K. Reynolds, P. C. Aikman, B. Lupoli, and D. E. Beever. 2002. Effects of abomasal vegetable oil infusion on splanchnic nutrient metabolism in lactating dairy cows. J. Dairy Sci. 85:1804-1814.

Bradford, B. J., and M. S. Allen. 2005. Phlorizin administration increases hepatic gluconeogenic enzyme mRNA abundance but not feed intake in late-lactation dairy cows. J. Nutr. 135:2206-2211.

Bradford, B. J., and M. S. Allen. 2007. Depression in feed intake by a highly fermentable diet is related to plasma insulin concentration and insulin response to glucose infusion. J. Dairy Sci. 90:38383845 .

Brindle, N. P. J., V. A. Zammit, and C. I. Pogson. 1985. Regulation of carnitine palmitoyltransferase activity by malonyl-CoA in mitochondria of sheep liver, a tissue with low capacity for fatty acid synthesis. Biochem. J. 232:177-182.

Broderick, G. A., and J. H. Kang. 1980. Automated simultaneous determination of ammonia and total amino acids in rumen fluid and in vitro media. J. Dairy Sci. 63:64-75.

Carlson, D. B., N. B. Litherland, H. M. Dann, J. C. Woodworth, and J. K. Drackley. 2007. Dietary L-carnitine alters periparturient nutrient metabolism and lactation in multiparous cows. J. Dairy Sci. 90:3421-3441.
Choi, B. R., and M. S. Allen. 1999. Intake regulation by volatile fatty acids and physical fill. S. Afr. J. Anim. Sci. 29(ISRP):40-41. (Abstr.)

Cochran, R. C., D. C. Adams, J. D. Wallace, and M. L. Galyean. 1986. Predicting the digestibility of different diets with internal markers: Evaluation of four potential markers. J. Anim. Sci. 63:1476-1483.

Dado, R. G., and M. S. Allen. 1993. Continuous computer acquisition of feed and water intake, chewing reticular motility, and ruminal pH of cattle. J. Dairy Sci. 76:1589-1600.

Davis, C. L. 1967. Acetate production in the rumen of cows fed either control or low-fiber, high-grain diets. J. Dairy Sci. 50:1621-1625.

Dijkstra, J., H. Boer, J. Van Bruchem, M. Bruining, and S. Tamminga. 1993. Absorption of volatile fatty acids from the rumen of lactating dairy cows as influenced by volatile fatty acid concentration, $\mathrm{pH}$ and rumen liquid volume. Br. J. Nutr. 69:385-396.

Faulkner, A., and H. T. Pollock. 1986. Propionate metabolism and its regulation by fatty acids in ovine hepatocytes. Comp. Biochem. Physiol. B 84:559-563.

Friedman, M. I. 1995. Control of energy intake by energy metabolism. Am. J. Clin. Nutr. 62:1096S-1100S.

Friedman, M. I., M. G. Tordoff, and I. Ramirez. 1986. Integrated metabolic control of food intake. Brain Res. Bull. 17:855-859.

Goering, H. K., and P. J. Van Soest. 1970. Forage Fiber Analysis (Apparatus, Reagents, Procedures, and Some Applications). Agricultural Handbook no. 379. ARS-USDA, Washington, DC.

Hach, C. C., B. K. Bowden, A. B. Lopelove, and S. V. Brayton. 1987. More powerful peroxide Kjeldahl digestion method. J. AOAC 70:783-787.

Jesse, B. W., R. S. Emery, and J. W. Thomas. 1986. Control of bovine hepatic fatty acid oxidation. J. Dairy Sci. 69:2290-2297.

Karkalas, J. 1985. An improved enzymatic method for the determination of native and modified starch. J. Sci. Food Agric. 36:10191027.

King, M. T., and P. D. Reiss. 1985. Separation and measurement of short-chain coenzyme A compounds in rat liver by reversedphase high-performance liquid chromatography. Anal. Biochem. 146:173-179

Knapp, J. R., H. C. Freetly, B. L. Reis, C. C. Calvert, and R. L. Baldwin. 1992. Effects of somatotropin and substrates on patterns of liver metabolism in lactating dairy cattle. J. Dairy Sci. 75:1025-1035

Langhans, W., C. Leitner, and M. Arnold. 2011. Dietary fat sensing via fatty acid oxidation in enterocytes: Possible role in the control of eating. Am. J. Physiol. Regul. Integr. Comp. Physiol. 300:R554-R565.

Langhans, W., and E. Scharrer. 1992. Metabolic control of eating. World Rev. Nutr. Diet. 70:1-67.

Larsen, M., and N. B. Kristensen. 2009. Effect of abomasal glucose infusion on splanchnic and whole body glucose metabolism in periparturient dairy cows. J. Dairy Sci. 92:1071-1083.

Leury, B. J., L. H. Baumgard, S. S. Block, S. Nthabisheng, R. A. Ehrhardt, R. P. Rhoads, D. E. Bauman, A. W. Bell, and Y. R. Boisclair. 2003. Effect of insulin and growth hormone on plasma leptin in periparturient dairy cows. Am. J. Physiol. Regul. Integr. Comp. Physiol. 285:R1107-R1115.

Lowe, D. M., and P. K. Tubbs. 1985. Succinylation and inactivation of 3-hydroxyl-3-methylglutaryl-CoA synthase by succinyl-CoA and its possible relevance to the control of ketogenesis. Biochem. J. $232: 37-42$.

Murphy, M. R., C. L. Davis, and G. C. McCoy. 1983. Factors affecting water consumption by Holstein cows in early lactation. J. Dairy Sci. $66: 35-38$.

NRC. 2001. Nutrient Requirements of Dairy Cattle. 7th rev. ed. Washington: National Academy of Science.

Oba, M., R. L. Baldwin VI, and B. J. Bequette. 2004. Oxidation of glucose, glutamate, and glutamine by isolated ovine enterocytes in vitro is decreased by the presence of other metabolic fuels. J. Anim. Sci. 82:479-486.

Oba, M., and M. S. Allen. 2003a. Effects of corn grain conservation method on feeding behavior and productivity of lactating dairy 
cows at two dietary starch concentrations. J. Dairy Sci. 86:174183.

Oba, M., and M. S. Allen. 2003b. Dose-response effects of intraruminal infusion of propionate on feeding behavior of lactating cows in early or midlactation. J. Dairy Sci. 86:2922-2931.

Oba, M., and M. S. Allen. 2003c. Extent of hypophagia caused by propionate infusion is related to plasma glucose concentration in lactating dairy cows. J. Nutr. 133:1105-1112.

Reynolds, C. K. 1995. Quantitative aspects of liver metabolism in ruminants. Page 351-372 in Ruminant Physiology: Digestion, Metabolism, Growth and Reproduction. W. von Englehardt, S. Leonhard-Marek, G. Breves, D. Geisecke, ed. Ferdinand Enke Verlag, Stuttgart, Germany.

Reynolds, C. K., P. C. Aikman, B. Lupoli, D. J. Humphries, and D. E. Beever. 2003. Splanchnic metabolism of dairy cows during the transition from late gestation through early lactation. J. Dairy Sci. $86: 1201-1217$.
Ricks, C. A., and R. M. Cook. 1981. Regulation of fatty acid uptake by mitochondrial acyl CoA synthetases of bovine liver. J. Dairy Sci. 64:2324-2335.

Sutton, J. D., M. S. Dhanoa, S. V. Morant, J. France, D. J. Napper, and E. Schuller. 2003. Rates of production of acetate, propionate, and butyrate in the rumen of lactating dairy cows given normal and low-roughage diets. J. Dairy Sci. 86:3620-3633.

Van Soest, P. J., J. B. Robertson, and B. A. Lewis. 1991. Methods for dietary fiber, neutral detergent fiber, and nonstarch polysaccharides in relation to animal nutrition. J. Dairy Sci. 74:3583-3597.

Wildman, E. E., G. M. Jones, P. E. Wagner, R. L. Boman, H. F. Troutt Jr., and T. N. Lesch. 1982. A dairy cow body condition scoring system and its relationship to selected production characteristics. J. Dairy Sci. 65:495-501.

Woodford, S. T., M. R. Murphy, and C. L. Davis. 1984. Water dynamics of dairy cattle as affected by initiation of lactation and feed intake. J. Dairy Sci. 67:2336-2343. 